Editorial

\title{
Special Issue “Laboratory Geosciences: Modelling Surface Processes" in Geosciences
}

\author{
Michael Nones $+(\mathbb{D}$ \\ Interdepartmental Centre for Industrial Research in Building and Construction-Fluid Dynamics Unit, \\ University of Bologna, Via del Lazzaretto 15/5, 40131 Bologna, Italy; michael.nones@unibo.it \\ † Present address: Hydrology and Hydrodynamics Department, Institute of Geophysics-Polish Academy of \\ Sciences, Ksiecia Janusza 64, 01-452 Warsaw, Poland.
}

Received: 17 October 2018; Accepted: 23 October 2018; Published: 25 October 2018

check for updates

\section{Editorial}

In the last decades, new and advanced measurement techniques have been developed to track the dynamics of surface processes and the formation of river bedforms, bars and island as well as complex fluvial networks, gullies and rills by means of small-scale laboratory experiments, aiming to integrate and support mathematical models [1] and field observations [2,3].

In fact, to date, many numerical codes can dynamically reproduce the evolution of fluvial environments and landscapes in general as forced by atmospheric drivers like rainfall and flowing water, but only a very scarce research is available on the reproduction of the involved phenomena from a physical point of view, with a particular emphasis on the laboratory scale. To fill this gap, on the one hand new measurement techniques (e.g., structure-from-motion, LiDAR, motion and depth detectors, image processing, high-resolution cameras, PIV/PTV techniques, etc.) can be adopted, designing appropriate laboratory experiments that can provide additional insights into the dynamic evolution of landscapes, possibly involving low-cost apparatus [4,5]. On the other hand, more effort is needed to appropriately address the temporal and spatial scales [6] and for the elaboration of the results, extrapolating physically-based relationships and general approaches that can be extended beyond the single experiment, evaluated and applied in different contexts.

This Special Issue on the reproduction of landscape evolution at the laboratory scale shows new measurement techniques with the associated pros and cons, and proposes different approaches depending on the phenomenon under analysis. The three applications reported here pointed out the capabilities of image-processing techniques in tracking the changes typically observed in fluvial environments involving relatively easy-to-use but very reliable methods. Indeed, as can be seen in the following, images can be handled to describe the dynamics associated with very small sediments, but also to track the movements of coarser material.

As a first example, Radice and Zanchi [7], using a tilting flume with a rectangular cross-section located at the Polytechnic University of Milan, Italy, showed that, at the laboratory scale, the reproduction of the propagation of aggrading and degrading sediment fronts requires the simultaneous measurement of the sediment feeding rate, the profile of the free surface, and the flume bed elevation. In their study, five action cameras and different image-processing techniques were employed to automatically measure all the quantities with an adequate temporal resolution. The measurement of the sediment feeding rate was determined by analyzing the surface velocity of the sediments that flow along a vibrating channel at the upstream feeder via the particle image velocimetry. The profile of the free surface was measured by shooting an array of piezometers connected to the flume. Each piezometer pipe contained a buoyant black sphere that could be recognized by particle identification, thus determining the elevation of the free surface above the piezometric probe. The bed profile along the flume was measured at any instant by edge detection, locating the transition from a 
water layer to a sediment layer in images taken from the side of the flume. Based on the results of a prototypal experiment, the potentialities and limitations of the proposed methods are presented and discussed, together with some prospects for the future use of such techniques.

The work developed by Noack et al. [8] presents a novel high-resolution photogrammetric measuring technique (PHOTOSED) to evaluate the erosion of cohesive sediments or cohesive/non-cohesive sediment mixtures. Installed on a flume located at the University of Stuttgart, Germany, PHOTOSED uses a semiconductor laser to project a pseudo-random pattern of light points on a sediment surface and applies the dense optical flow (DOF) algorithm to measure the erosion volume based on the displacement of the projected light points during the sediment erosion process. Based on intensive calibration and verification experiments, the accuracy and applicability of the method have been validated for a wide range of erosion volumes, encompassing several orders of magnitude, as required for investigations of natural sediment mixtures. In particular, the authors proved that, with this high spatial resolution, the substantial variability of erosion rates during exemplary erosion experiments can be detected, allowing for further investigations of the erosive processes in cohesive/non-cohesive sediment mixtures.

Similarly to the previous study [8], the research developed by Termini and Di Leonardo [9] at the University of Palermo, Italy, focuses on the use of image-processing methods, in particular applying a large scale particle image velocimetry (LSPIV) technique. Their paper explores the efficiency of this digital image technique and the associated algorithms for the remote monitoring of surface velocity and discharge measurement in the case of hyper-concentrated flow reproduced in the laboratory. The quantification of the errors in estimating the surface velocity using image processing is complex because it depends on many factors characterizing either the experimental conditions or/and the processing algorithm. In the present work, the authors estimated the errors due either to the acquisition time and to the size of the interrogation areas. Using data collected in a scale laboratory flume, the research points out that the number of frames used in the processing procedure strongly affects the surface velocity values, indeed, the estimation error decreases as the number of frames increases, reaching an almost constant value for more than 1200 frames. The size of the interrogation area plays also an important role in the flow velocity estimation: a reduction of the size of the interrogation area compared to its original size permits us to obtain low velocity estimation error values, but involves a computational effort that can become too excessive for some applications. Thanks to the ability to effectively estimate the surface flow velocity, digital image techniques can also be applied to derive the discharge that flows along the flume.

The three examples reported in this Special Issue highlight the necessity to deeply study the evolution of fluvial landscapes by means of laboratory experiments, combining traditional and innovative techniques towards the use of low-cost devices. In fact, thanks to the decrease in the cost of cameras and image-processing software, the acquisition and associated analysis of automatically acquired images are becoming widely used in laboratories worldwide, giving rise to a renewed impulse in the experimental geosciences as a support tool for modelling approaches. The Guest Editor gratefully acknowledges the many colleagues involved in assembling the papers and publishing this Special Issue of Geosciences, from the contributing authors to the reviewers and the entire editorial team.

Author Contributions: M.N. conceived the Special Issue, invited the authors and handled their contributions, summarized in this editorial.

Funding: This research received no external funding.

Acknowledgments: The Editor would like to gratefully thank all the authors that have contributed to the Special Issue.

Conflicts of Interest: The author declares no conflict of interest. 


\section{References}

1. Czuba, J.A.; Foufoula-Georgiou, E.; Gran, K.B.; Belmont, P.; Wilcock, P.R. Interplay between spatially explicit sediment sourcing, hierarchical river-network structure, and in-channel bed material sediment transport and storage dynamics. J. Geophys. Res. Earth Surf. 2017, 122, 1090-1120. [CrossRef]

2. Luffman, I.; Nandi, A.; Luffman, B. Comparison of Geometric and Volumetric Methods to a 3D Solid Model for Measurement of Gully Erosion and Sediment Yield. Geosciences 2018, 8, 86. [CrossRef]

3. Nones, M.; Archetti, R.; Guerrero, M. Time-Lapse Photography of the Edge-of-Water Line Displacements of a Sandbar as a Proxy of Riverine Morphodynamics. Water 2018, 10, 617. [CrossRef]

4. Varrani, A.; Caviedes-Voullième, D.; Hinz, C. Dynamic mapping of surface topography at rainfall events. In Proceedings of the 5th IAHR Europe Congress, Trento, Italy, 12-14 June 2018. [CrossRef]

5. Caviedes-Voullième, D.; Juez, C.; Murillo, J.; García-Navarro, P. 2D dry granular free surface flow over complex topography with obstacles. Part I: Experimental study using a consumer-grade RGB-D sensor. Comput. Geosci. 2014, 73, 177-197. [CrossRef]

6. Parsons, A.J.; Brazier, R.E.; Wainwright, J.; Powell, D.M. Scale relationships in hillslope runoff and erosion. Earth Surf. Process. Landf. 2006, 31, 1384-1393. [CrossRef]

7. Radice, A.; Zanchi, B. Multicamera, Multimethod Measurements for Hydromorphologic Laboratory Experiments. Geosciences 2018, 8, 172. [CrossRef]

8. Noack, M.; Schmid, G.; Beckers, F.; Haun, S.; Wieprecht, S. PHOTOSED—PHOTOgrammetric Sediment Erosion Detection. Geosciences 2018, 8, 243. [CrossRef]

9. Termini, D.; Di Leonardo, A. Efficiency of a Digital Particle Image Velocimetry (DPIV) Method for Monitoring the Surface Velocity of Hyper-Concentrated Flows. Geosciences 2018, 8, 383. [CrossRef]

(C) 2018 by the author. Licensee MDPI, Basel, Switzerland. This article is an open access article distributed under the terms and conditions of the Creative Commons Attribution (CC BY) license (http:/ / creativecommons.org/licenses/by/4.0/). 